\title{
Expert guidance on hand for clinicians
}

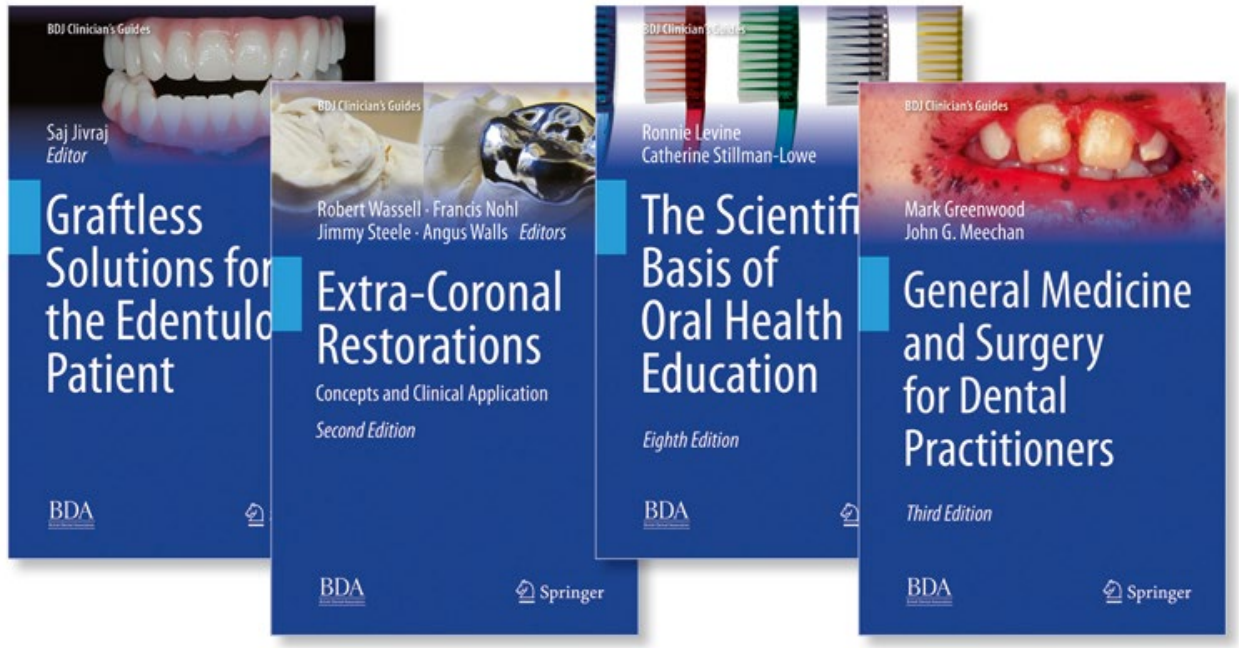

Dental professionals now have access to expert guidance in the newly published BDA book General Medicine and Surgery for Dental Practitioners. ${ }^{1}$

The book, published by the BDA and Springer Nature is aimed at practising clinicians and is now in its third edition.

It provides a detailed overview of the medical and surgical conditions that affect patients seen in everyday dental practice.

The authors, Mark Greenwood of the School of Dental Sciences at Newcastle University and John Meechan, said that because patients were surviving longer due to medical advances, dentists were increasingly faced with complex conditions and possibly some that they have not previously encountered.

Therefore, their book covers treatment advice, drug interactions, and the impact of general medical and surgical conditions on treatment planning in the dental context.

In addition to chapters on the implications for dental practice of disorders of each of the different body systems and immunological and infectious diseases, it also covers other important aspects in particular patient groups such as cancer patients, older people, and the paediatric population.

The authors said: 'Overall, this book provides dentists with a practical, logical, and convenient guide of great value, helping to update knowledge and foster improved patient care.'

The BDA and Springer Nature also have several other clinician's guide books available including Graftless Solutions for the Edentulous Patient, ${ }^{2}$ Extra-Coronal
Restorations: Concepts and Clinical Application $^{3}$ and The Scientific Basis of Oral Health Education-8 8 th Edition. ${ }^{4}$

All of these titles are available to buy at the BDA shop (https://shop.bda.org/) where BDA members are entitled to a more than $20 \%$ discount.

Free chapters will be available from these books at the following links:

- Graftless Solutions for the Edentulous Patient: Chapter 4: Comprehensive Integrated Digital Workflow to Guide Surgery and Prosthetics for Full-Arch Rehabilitation: A Narrative Review - https://www.springer.com/gb/ book/9783319658575\#

- Extra-Coronal Restorations: Concepts and Clinical Application: Chapter 1: Introduction - https://www.springer.com/ us/book/9783319790923

- The Scientific Basis of Oral Health Education- 8th Edition: Chapter 1: Health Education - https://www.springer.com/la/ book/9783319982069

- General Medicine and Surgery for Dental Practitioners: Chapter 1: History Taking and Examination of the Clothed Patient - https://www.springer.com/gb/

\section{References}

1. Greenwood M, Meechan J G. General Medicine and Surgery for Dental Practitioners. London: Springer Nature, 2019.

2. Jivraj S. Graftless Solutions for the Edentulous Patient. London: Springer Nature, 2018.

3. Wassell R, Nohl F, Steele J, Walls A. Extra-Coronal Restorations: Concepts and Clinical Application. London: Springer Nature, 2018.

4. Levine R, Stillman-Lowe C. The Scientific Basis of Oral Health Education- 8th Edition. London: Springer Nature, 2018. book/9783319977362.

\section{Student drive to boost World Oral Health Day 2019}

The BDA is encouraging dental students to take part in this year's activities for World Oral Health Day ${ }^{1}$ held on 20 March 2019 by giving oral health promotion talks to local nurseries, primary schools or children's centres.

World Oral Health Day is celebrated globally every year on $20 \mathrm{March}$, organised by FDI World Dental Federation and claims to be the largest global awareness campaign on oral health.

The event is designed to spread messages about good oral hygiene practices to adults and children while demonstrating the importance of

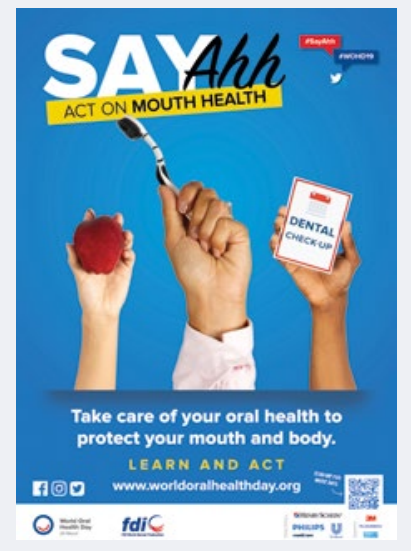

optimal oral health in maintaining general health and well-being.

The BDA said dental students could plan an oral health promotional visit to a childcare setting at any time, but if it was organised in the run up to, or just after, 20 March, this meant the Association could promote the effort alongside the World Oral Health Day campaign.

Various resources to support students were available including information on brushing top tips and myth busters; sugar and children's oral health top tips; BDA sugar poster; and the loan of BDA oral health promotional items such as stickers, Playmobile dental set, dentist dressing up clothes, a tooth dragon and books.

\section{References}

1. FDI World Dental Federation. World Oral Health Day. Available at http://www.worldoralhealthday. org/ (accessed February 2019). 